\title{
New Technologies and the Convergence of Libraries, Archives, and Museums
}

LIBRARIANS AND ARCHIVISTS who work in museums live a kind of double life. On the one hand, we consider ourselves information professionals: we belong to organizations such as SAA, ALA, SLA, or ARLIS, and we adhere to archival and library standards and ethics. On the other hand, museum departments operate within an organizational structure that is very different from a library, with dissimilar priorities and a unique institutional culture. Our day-to-day job requires a level of internal collaboration if we are to interpret and bridge these differences successfully.

When I became involved in planning, and later editing and coauthoring, a new edition of SAA's Museum Archives: An Introduction, ${ }^{1}$ it was clear to me that the manual had to address this issue of internal collaboration. In addition to covering the basics of how archives function, we needed to identify the ways that our particular institutional culture and its priorities impact our work. Our goal was twofold: to describe that culture for archivists who had never worked in a museum, as well as to teach museum staff members who suddenly find themselves with archival responsibilities how to manage archival collections.

About a year ago, I was given the exciting task of creating a new department that would be responsible for all digital imaging activities at the Brooklyn Museum, ${ }^{2}$ including scanning and photography, asset management, and permission and licensing. After having spent many happy years as the museum archivist, this was a wonderful promotion with a stimulating set of new responsibilities. The work we

1. Deborah Wythe, ed., Museum Archives: An Introduction, 2nd ed. (Chicago: Society of American Archivists, Museum Archives Section), 2004.

2. The Brooklyn Museum (www.brooklynmuseum.org/) is an encyclopedic art museum with collections of American and European paintings, sculpture, decorative arts, costumes, textiles, prints, drawings, and photographs, and contemporary art; Asian art; as well as art from the Americas, Africa, and the Pacific Islands and Egyptian, Classical, and Middle Eastern art. The museum maintains an art reference library and the Wilbour Library of Egyptology, which includes more than 200,000 volumes. The institutional museum archives contain about 2,000 linear feet of material, and rapidly growing digital collections comprise more than 20,000 images of objects as well as items from the museum archives and libraries. 
had been doing to establish a digital imaging program in the archives and library had suddenly expanded to include the whole institution. I was no longer dealing with the museum as it had been, but working with other staff members to shape where we were going as an institution in the new digital world. It proved to be a very interesting and illuminating year in the Brooklyn Museum microcosm, and one that may reveal a bit about where our profession is headed. Museum staffs are made up of curators, collections managers, conservators, registrars, art handlers, administrators, librarians, and archivists - all of whom have different interests, educational backgrounds, and job skills. While there is one large umbrella organization, the American Association of Museums (AAM), there are also many other professional organizations that address specific subject or skill areas. There is really no single professional title that encompasses everyone who works in a museum. When I assumed my new position, I was faced with a quandary in filling out those inevitable forms and questionnaires that ask for "occupation." Should I write "museum professional" or "digital imaging manager"? By comparison, "archivist" was easy, even if most people had no idea what it meant.

A librarian is a librarian — a reference librarian, a systems librarian, or a cataloger-whether he or she works for a university, an independent research library, a corporate library, or a school. The same can be said of archivists. We share similar training, skills, and tasks no matter where we work.

What is it that has brought libraries and archives closer and closer together over the past decades and allowed us to develop so many collaborative techniques and projects? I would suggest three things. First, we share a central core of professional skills and tenets, as I have noted. Second, we adhere to something that could only have developed within such a unified environment, namely the shared development and adoption of standards. Third, we tend wholeheartedly to embrace new technologies as a means of providing access to our collections. Could the MARC format have been developed without all three of these elements? Could it have been successfully expanded to include archival and manuscript materials without them? Could the Encoded Archival Description (EAD) standard have been developed? I do not think so.

Where does this leave museums? And why is it only at this late date that we have started to think of "cultural heritage organizations" as a single group, an idea that seems to be coming primarily from government funding agencies and other grant programs, and, to some extent, from the libraries and archives community? Are museum curators promoting this idea? Museum conservators? Museum educators? Not really. Why does it seem so difficult to think about collaborations that include the "M" of libraries, archives, and museums? Museums have such "good stuff." 
How can we incorporate it? What are the stumbling blocks? What can museums bring to this effort?

From my perspective, although museums embrace the third element, technology, we have come to do so much later than libraries and archives, and we tend to be distinctive soloists rather than members of a closely knit ensemble. Cross-institutional collaborations are nearly impossible without solid progress in agreement on standards. Professional standards have been under development in the museum world for years, but never fully adopted; for example, there is certainly no agreement about what public access should be. Witness the difference between museum Web sites and library or archives Web sites: what is front and center? Not museum collection catalogs, at least not yet. But why not?

Museum staff members rarely talk about "access to collections." We have "visitors," not "users." Museums have "collections management systems," not "catalogs," and these systems traditionally have been accessible only to internal staff. They are primarily used by curators to create exhibitions, develop publications, and provide the content that now is included on our Web sites-what we call "interpretation." In my experience, museum curators are highly reluctant to put object information or images out on the Web without, at the very least, a "chat label" in addition to the "tombstone," that is, the basic descriptive data plus a paragraph with some additional background information. Curators are much more likely to create an online exhibition by grouping objects and providing context than simply listing the contents of their collections. As a result, visitors to our museum or our Web site are guided through the collections, not simply given access to a catalog.

There is, of course, also a tradition of mediated access to collections in the library and archives world. Finding aids provide both context and description, and the reference interview is a perfect example of an interpretative interaction between user and information professional. Libraries and archives also produce exhibitions and have been putting increasingly greater effort into them. Museums, however, have traditionally started with an exhibition, as exhibitions and installations are considered a central part of our mission. Interpretation, which I would argue is a more forceful act than mediation, is deeply embedded in our institutional culture. Collections exist to support programming of all kinds. They are thus key to the mission of the museum and help to support it, but collecting itself is not the mission.

One class of museum visitors-namely scholars who need direct access to the collections - has traditionally been assisted on a one-to-one basis by museum staff. Curators generally value that interaction highly, since they, too, have a deep research interest in the content of the collections they oversee. Yet, while libraries 
and archives regard scholarly researchers as a large and important part of their audience, museums do not consider them as their primary audience. In other words: why do people go to a library or an archive? To read, to look up information, to borrow books, to do research — at whatever level, it is a very individualized experience. Why do people go to a museum? To see something, perhaps to learn something. Often they go with someone - a friend or family member-and sometimes they are accompanied by a docent, lecturer, or tour guide. A museum visit tends to be an interpersonal experience.

With respect to these differences, in what ways do we see museums converging with libraries and archives, and what is each of them contributing? Clearly, libraries and archives are adopting some aspects of museum practice: acquiring and managing collections of artifactual objects and realia, establishing onsite and Web exhibition programs, and increasing outreach activities aimed at drawing people to their collections. Techniques borrowed from museums include technical skills such as registration and collections management; visually striking exhibition, gallery, and Web site design; and the creation of interpretive content for exhibition didactics, object labeling, and publications.

Are museums likewise adopting library and archives techniques? Very slowly, but it is starting to happen. There has been increasing momentum to provide access to collection catalogs through the Web as more and more museums are creating digital representations of their holdings. Standards for describing objects are starting to be developed, though they are far less stable than MARC, and museums rarely have the trained and dedicated catalogers needed to implement strict standards. Interestingly, many of the new museum digital asset managers have experience in the library or archives world, as I do. I believe that we will see a melding of approaches as museums start to implement digital asset management systems and work out how to present digital materials on the Web. I do not think these systems will look like library OPACs, however, as the standards-based catalogs will most likely be working behind the scenes.

Some exciting new initiatives are also coming from outside our institutions. Aggregators of "cultural objects," like RLG, ArtStor, Scholars Resource, and Saskia, are approaching museums with proposals to bring together object images and descriptive information into large cross-institutional databases for the benefit of scholars and educators. Personalized image tagging, featured on Web sites like Flickr, is being considered in the museum community as a potential means for enhancing our connection with our audiences. Likewise, museums are quickly adopting blogs as a way of providing personalized, informal information about the museum, its programs, and its collections. We are using handheld devices or PDAs to provide 
programmed or customized tours. We are allowing Web visitors to create a custom selection of "my museum" objects and we are providing e-commerce links to marketers offering products developed from collection objects.

I am very optimistic about the new "digital world order." I believe that we can adapt and use online tools to transform our professions by making the most of our collections and by providing a variety of services to the widest audiences possible. I do not think that we will achieve success simply by modifying past practice: new tools demand new techniques. Museums are breaking new ground, exploring interesting and challenging approaches to collection exploration and interpretation. As one of our information technologists said, "Nobody wants to read a finding aid or dig through an online catalog; they just want to find what they are interested in." Libraries and archives may have the technology and standards, but museums have the presentation skills. By drawing from both domains, we can move closer to a common goal of helping people to explore the world in exciting new ways, with the technology becoming ever more invisible. This is where I see our futures as libraries, archives, and museums converging.

\section{David M. Lesser Fine Antiquarian Books LLC \\ One Bradley Road \#302, Woodbridge, CT 06525 \\ Tel: (203) 389-8111 Fax: (203) 389-9113 \\ Email:dmlesser@lesserbooks.com \\ Website: http://www.lesserbooks.com}

